\title{
Higher single dose of bortezomib plus thalidomide and dexamethasone is a promising therapy for newly diagnosed multiple myeloma
}

\author{
Peipei Xu, Rongfu Zhou, Jingyan Xu, Jian Ouyang, Xiaoyan Shao, Bing Chen \\ Department of Hematology, the Affiliated Drum Tower Hospital of Nanjing University Medical School, Nanjing 210008, China \\ Contributions: (I) Conception and design: X Shao; (II) Administrative support: B Chen; (III) Provision of study materials or patients: R Zhou, J Xu; \\ (IV) Collection and assembly of data: J Ouyang; (V) Data analysis and interpretation: P Xu, X Shao; (VI) Manuscript writing: All authors; (VII) Final \\ approval of manuscript: All authors. \\ Correspondence to: Xiaoyan Shao, PhD; Bing Chen, PhD. Department of Hematology, the Affiliated Drum Tower Hospital of Nanjing University \\ Medical School, Nanjing 210008, China. Email: linda07xiaoyan@163.com; chenb211@163.com.
}

\begin{abstract}
Background: Bortezomib in combination with thalidomide and dexamethasone (VTD) has been widely used for newly diagnosed multiple myeloma (MM). The aim of this study was to evaluate the efficacy and safety of a new high-dose bortezomib plus thalidomide and dexamethasone as an induction and consolidation therapy regimen for $M M$.
\end{abstract}

Methods: A total of 93 patients with previously untreated symptomatic MM were enrolled in this singlecenter study. In group-1, 40 patients received bortezomib $1.6 \mathrm{mg} / \mathrm{m}^{2}$ and dexamethasone $40 \mathrm{mg}$ on days 1, 6 and 11, plus thalidomide $100 \mathrm{mg}$ on days 1-21 (VTD-1). In group-2, 53 patients received bortezomib $1.3 \mathrm{mg} / \mathrm{m}^{2}$ and dexamethasone $40 \mathrm{mg}$ on days $1,4,8$ and 11 in combination with thalidomide $100 \mathrm{mg}$ on days 1-21 (VTD-2).

Results: The odds ratio rates after 2 cycles of VTD and the best response during this study were $95 \%$ vs. 81.1\% ( $\mathrm{P}=0.044)$, and 95\% vs. 90.6\% ( $\mathrm{P}=0.349)$ in group-1 and group-2, respectively. The best CR rate in group-1 was higher than that in group-2 [52.5\% vs. $45.3 \%(\mathrm{P}=0.316)]$. In group-1, only 2 of 21 patients who achieved CR relapsed from the disease, as did 9 of 24 patients in group-2 ( $\mathrm{P}=0.031)$. The median PFS in group- 1 and group- 2 were 34 and 28.8 months $(\mathrm{P}=0.969)$, and the median OS in group- 1 and group-2 were 33.5 and 46.4 months $(\mathrm{P}=0.987)$. In group-1 and group-2, the median CD34 ${ }^{+}$cells of stem cell collection were $3.68 \times 10^{6}$ vs. $5.84 \times 10^{6}$ cells $/ \mathrm{kg}(\mathrm{P}=0.179)$. Patients in group-1 had a lower incidence of peripheral neuropathy than group-2 [32.5\% vs. $41.5 \%(\mathrm{P}=0.371)]$.

Conclusions: High-dose bortezomib at a dose of $1.6 \mathrm{mg} / \mathrm{m}^{2}$ in combination with thalidomide and dexamethasone was well tolerated and highly efficient as an induction and consolidation therapy for MM.

Keywords: Multiple myeloma (MM); proteasome inhibitors; higher single dose of bortezomib

Submitted Jun 25, 2018. Accepted for publication Apr 12, 2019.

doi: $10.21037 /$ tcr.2019.09.22

View this article at: http://dx.doi.org/10.21037/tcr.2019.09.22

\section{Introduction}

Multiple myeloma (MM) is the most frequent hematological malignancy originating from clonal plasma cells. The overall response rate of MM patients treated with conventional chemotherapeutic agents, such as melphalan, vincristine and adriamycin, is $60 \%$. Less than $5 \%$ patients achieve a complete response (CR), and the median survival is 2-3 years (1). Since 1996, when Attal et al. published results indicating that high-dose chemotherapy (HDC) followed by autologous stem cell transplantation (ASCT) could achieve a higher response rate (RR), longer eventfree survival (EFS) and longer overall survival (OS) of MM 
patients, this approach has become part of standard therapy for transplant-eligible patients (2-4).

Over the past decade, with the advent of novel agents such as immunomodulatory drugs (IMiDs) and proteasome inhibitors, the treatment of newly diagnosed MM has improved dramatically (5). In several clinical trials (6-8), the ORR of MM patients treated with bortezomib, thalidomide and dexamethasone (VTD) was higher than $90 \%$, and the CR was at least $27 \%$. However, due to disease relapse or refractory to regimens, patients with newly diagnosed MM who received current novel therapeutic approaches, mainly bortezomib and IMiDs, achieved dissatisfactory survival outcomes. MM was still an incurable disease, and treatments required further exploration regarding various combinations, sequences, doses and durations of active drugs to achieve rapid and deeper response and maintain remission to prolong survival. On the basis of several vital clinical trials (9-12), glucocorticoids, IMiDs plus proteasome inhibitors has become the most common induction and consolidation therapy, and studies demonstrated that administration bortezomib once a week instead of twice weekly can diminish treatment-related toxicity to greatly improve quality of life. However, Brioli et al. demonstrated that the CR rate was reduced from $27 \%$ to $20 \%$ after a prolonged injection period of bortezomib from twice a week to once a week (13). For patients, the main considerations in $\mathrm{MM}$ treatment management, such as choice of therapy regimens and drop-out from treatment, were effectiveness and cost-effectiveness.

To explore optimum dosage and duration of bortezomib in that combination to achieve a higher response rate and lower costs for patients, we conducted single-center research to evaluate the efficiency and safety of bortezomib at $1.6 \mathrm{mg} / \mathrm{m}^{2}$ on day 1 , day 6 and day 11 in a 21 -day cycle setting.

\section{Methods}

\section{Patients}

Between January 2012 and August 2016, a total of 93 patients under age 85 with symptomatic, measurable and newly diagnosed MM were enrolled in this study. Exclusion criteria included the following: symptomatic congestive heart failure, unstable angina, and myocardial infarction within the past 6 months; left ventricular ejection fraction less than $40 \%$; grade 2 or higher peripheral neuropathy; and pulmonary diffusing capacity less than $50 \%$ of predicted. All patients provided written informed consent before participating in the research.

\section{Treatment}

To achieve rapid and deep response and prolong remission, the treatment of newly diagnosed MM was composed with sequential drug combinations and divided into 3 phases: induction, consolidation and maintenance therapy. In our research, all patients received a triple agent combination therapy, VTD, as the induction and consolidation therapy. They received thalidomide (100 mg/day for 12-18 months) as maintenance therapy to extend the duration of best response. In group-1, patients received subcutaneous bortezomib $1.6 \mathrm{mg} / \mathrm{m}^{2}$ and oral dexamethasone $40 \mathrm{mg}$ on days 1, 6 and 11, in combination with oral thalidomide $100 \mathrm{mg}$ on days 1-21 (VTD-1). For group-2, bortezomib was administered at a dose of $1.3 \mathrm{mg} / \mathrm{m}^{2}$ and oral dexamethasone $40 \mathrm{mg}$ on days $1,4,8$ and 11 , plus oral thalidomide $100 \mathrm{mg}$ on days 1-21 (VTD-2). Each patient received four cycles of VTD as the induction therapy to minimize tumor burden as much as possible. After achieving at least a partial response (PR), transplantation eligible patients received $200 \mathrm{mg} / \mathrm{m}^{2}$ melphalan and followed ASCT. To reduce aggressive subclones and secondary mutations, non-ASCT patients had 8-12 cycles of VTD as consolidation therapy to improve the quality of response $(14,15)$. The approach of treatment in this study is outlined in Figure 1.

\section{Criteria for evaluation}

Response assessments were carried out according to the uniform response criteria of the International Myeloma Working Group (IMWG) (16), and they were conducted before each course of treatment, treatment discontinuation or planned end of treatment. The primary end point was progression-free survival (PFS), which was defined as the interval from the date of the initiation of induction therapy to the disease progression, relapse, or death. The secondary end points included overall survival (OS, calculated from the date of diagnosis to death or when the patient was lost from follow-up), safety and tolerability, feasibility and quality of stem cell collection, and response rate at each step of the program. 


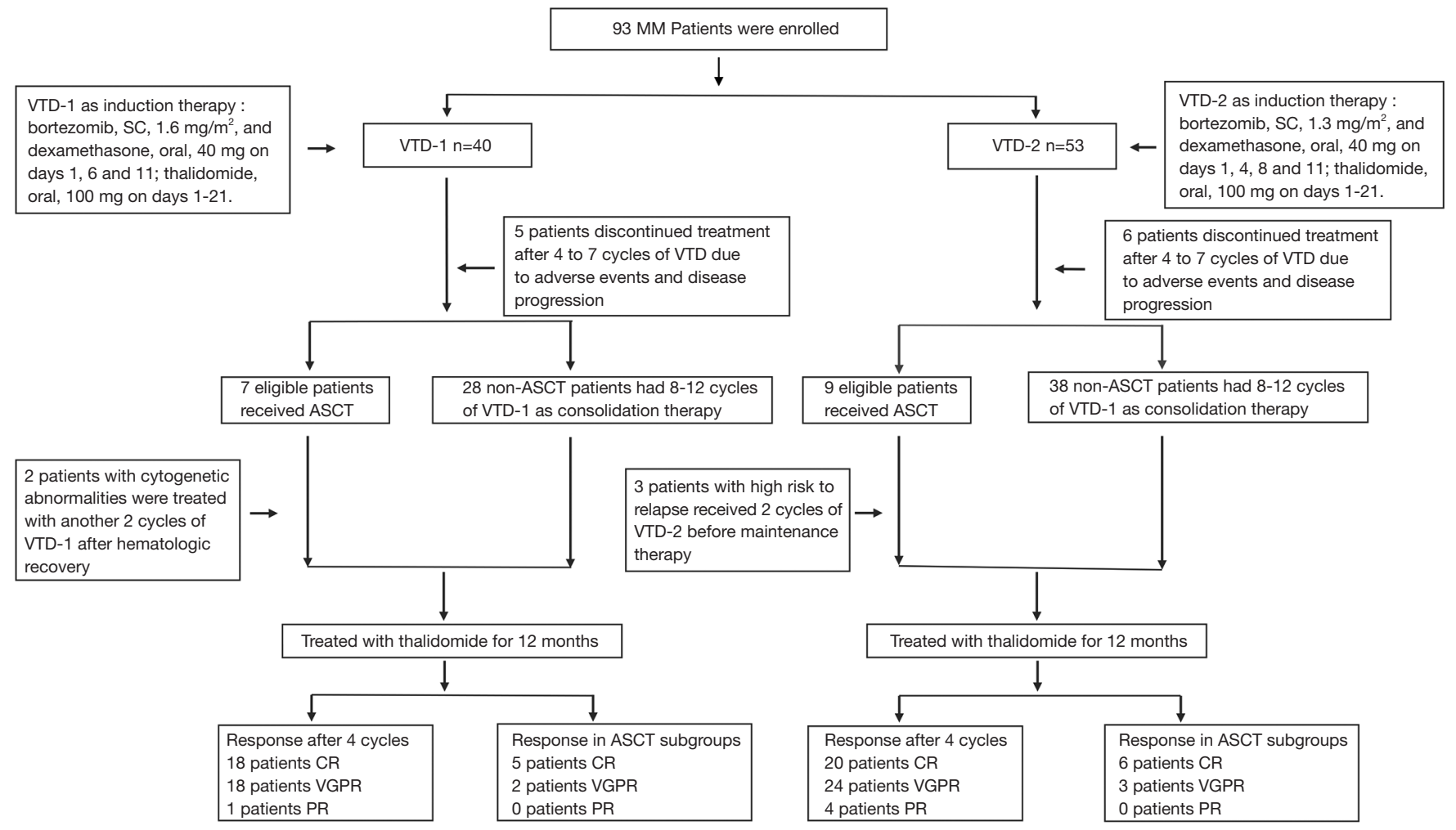

Figure 1 Flowchart of the treatment strategy. VTD, combination therapy of bortezomib, thalidomide plus dexamethasone; SC, subcutaneous; CR, complete response; VGPR, very good partial response; PR, partial response; ASCT, autologous stem cell transplantation.

\section{Statistical methods}

The Kaplan-Meier method was administered to analyze survival distribution, and the log-rank test was used to assess the significance of differences in survival curves. The associations between categorical variables were analyzed using Pearson chi-squared test. All data were statistically analysed using a commercially available statistical software package (SPSS 19.0; IBM Corp.). Differences were considered statistically significant when $\mathrm{P}$ values were $<0.05$.

\section{Results}

\section{Patients and treatments}

This study included 93 patients newly diagnosed with MM. The demographics and baseline characteristics of these patients are summarized in Table 1. The median age was 61 years (ranging from 41 to 83 years), and 56 patients were male $(60.2 \%)$. The bone marrow fluorescent in situ hybridization (FISH) analysis and chromosome examination were conducted for all patients, and cytogenetic abnormalities were detected in $40(43 \%)$ patients at their initial diagnosis of $M M$, including the presence of gain (1q), deletion (1p), deletion (17p), and deletion (13) mutations, $\mathrm{IgH}$ translocations, MYC translocations, trisomies and complex chromosomal abnormalities.

All patients received at least 4 cycles of VTD, excluding 5 patients with a poor response. The median treatment cycles for group-1 and group-2 were 5.55 and 5.47 cycles, respectively. Due to adverse events and disease progression, 5 patients in group- 1 and 6 patients in group- 2 discontinued treatment after 4 to 7 cycles of VTD. In group-1, 40 patients received VTD-1, and 7 eligible patients performed transplantation. After ASCT, 2 patients with cytogenetic abnormalities detected when diagnosed were treated with another 2 cycles of VTD-1 after hematologic recovery, and all of the 7 patients continued to receive thalidomide (100 mg/day for $12-18$ months) as maintenance therapy. In group-2, 53 patients were treated with VTD2, and 9 patients received ASCT. With high risk to relapse, 3 out of 9 patients received 2 cycles of VTD-2 before maintenance therapy. 
Table 1 The association between patients' baseline characteristics and different groups

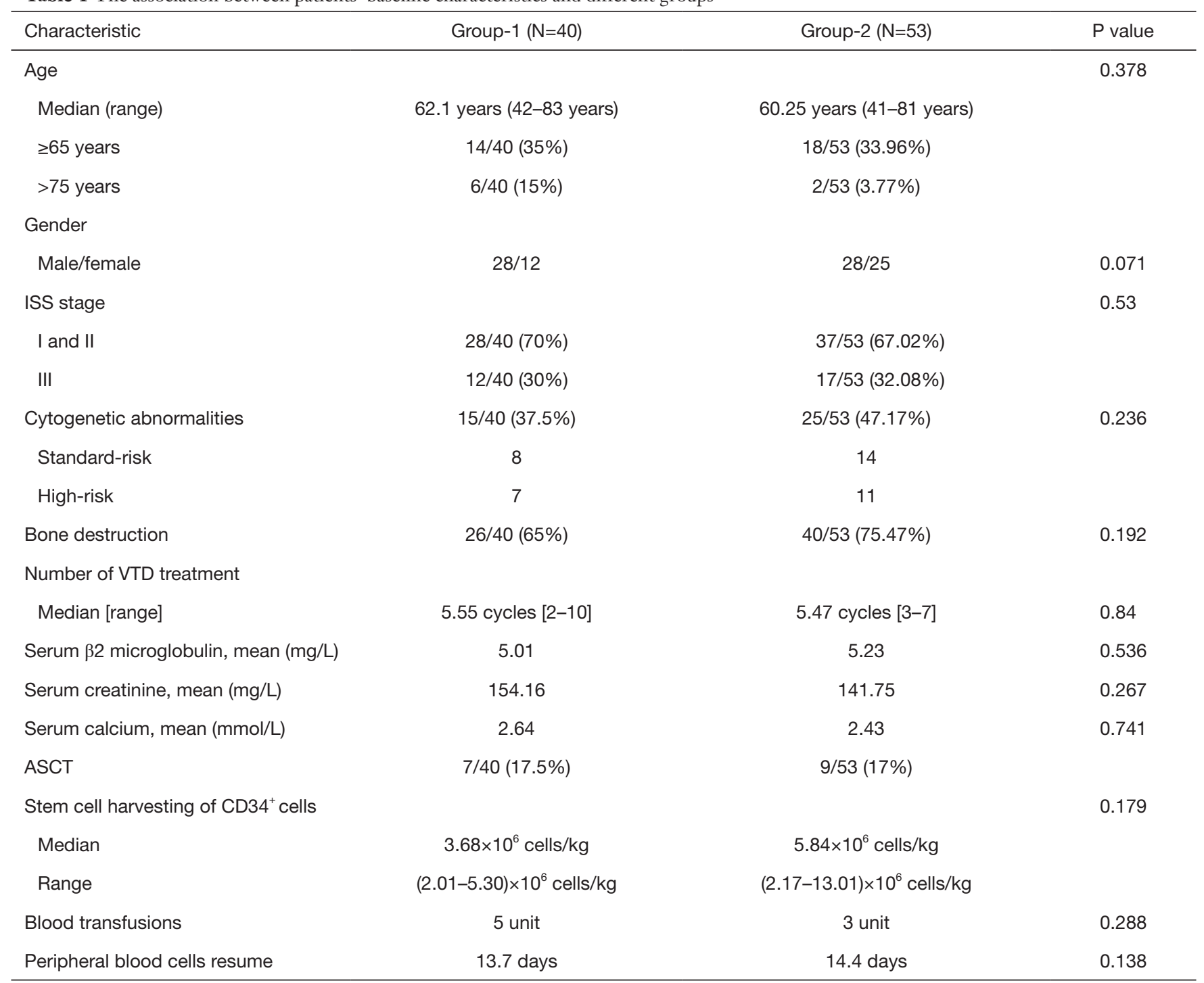

VTD, combination therapy of bortezomib, thalidomide plus dexamethasone; ASCT, autologous stem cell transplantation.

\section{Efficacy}

In group-1, with a median follow-up time of 18.77 months (a range 4 to 37 months), 9 patients (22.5\%) had relapsed, and 4 patients $(10 \%)$ had died due to the primary disease. In group-2, the relapse rate and mortality rate were $30.2 \%$ $(16 / 53)$ and $9.4 \%(5 / 53)$, and the median follow-up time was 20.3 months (range 7 to 56 months). No significant differences were observed between the relapse and mortality rates in these two groups $(\mathrm{P}=0.278$ and $\mathrm{P}=0.598)$. The median PFS in group-1 and group-2 was 34 months and 28.8 months $(\mathrm{P}=0.969$, Figure $2 A)$, respectively. Although the median $\mathrm{OS}$ in group-2 was much longer than in group-1 (46.4 vs. 33.5 months, Figure 2B), this finding was not statistically significant $(\mathrm{P}=0.987)$.

All patients were assessed for response during the program, and Table 2 lists the response rates after induction and ASCT, and best response. The odds ratio (OR) rates were $95 \%$ in group- 1 and $90.6 \%$ in group- 2 . There was no significant difference between these two groups $(\mathrm{P}=0.349)$. However, after 2 cycles of VTD, the OR in group- 1 was significantly higher than in group-2 (95\% vs. $81.1 \%$; $\mathrm{P}=0.044)$. The best $\mathrm{CR}$ rate in group- 1 was higher than in group-2 [52.5\% (21/40) vs. 45.3\% (24/53) $(\mathrm{P}=0.316)]$. Only 2 out of 21 patients who achieved CR relapsed 


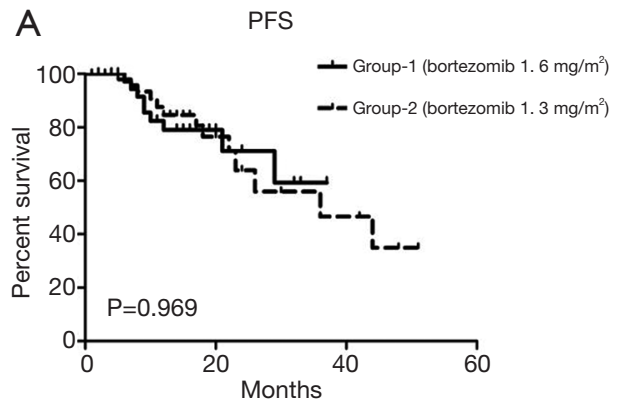

Number of group-1: 40 Number of group-2: 53

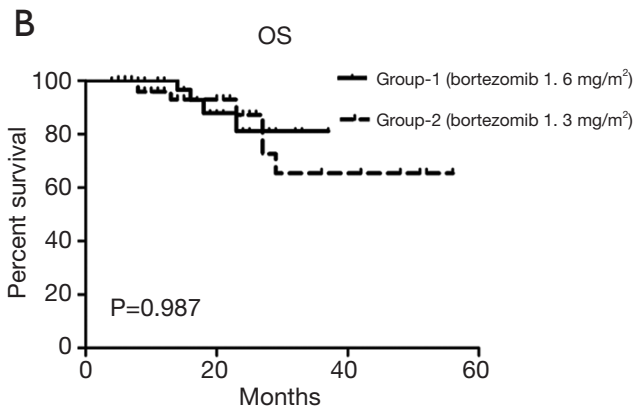

Number of group-1: 40 Number of group-2: 53

Figure 2 Survival (log-rank test) of patients. (A) Progression-free survival. (B) Overall survival.

from the disease in group-1, as did 9 out of 24 patients in group-2. The relapse rate between these two subgroups was statistically significant $[9.5 \%$ vs. $37.5 \%(\mathrm{P}=0.031)]$.

Before performing high-dose melphalan followed by ASCT, all transplantation eligible and willingness patients achieved at least PR. The response rate of these patients is described in Table 3. In group-1, the response of all 3 patients who achieved PR before ASCT had improved, 2 patients achieved CR, and 1 patient achieved very good partial response (VGPR) after ASCT. In group-2, 3 patients had an improved response from PR to VGPR, 1 patient went from PR to CR, and 2 patients went from VGPR to CR after ASCT.

\section{Safety}

Peripheral neuropathy $(\mathrm{PN})$ is one of the key toxicities of bortezomib-based treatment. In this study, therapy related $\mathrm{PN}$ was found in $32.5 \%$ of group-1 patients (13/40) and $41.5 \%$ of group-2 patients $(22 / 53)(\mathrm{P}=0.371)$ respectively. Only one patient with grade 3 sensory $\mathrm{PN}$ in group- 1 was detected after 2 cycles of VTD-1, and this patient received dose modification (bortezomib from 1.6 to $1.3 \mathrm{mg} / \mathrm{m}^{2}$ on day 1, 6 and 11) for another 3 cycles. In group-1, 5 patients received dose reduction of bortezomib from 1.6 to $1.3 \mathrm{mg} / \mathrm{m}^{2}$. In group-2, for 7 patients, the dose of bortezomib was decreased from 1.3 to $1.0 \mathrm{mg} / \mathrm{m}^{2}$.

Treatment-related hematologic toxicities including thrombocytopenia, neutropenia and anemia were transient and cyclical. During treatment intermission, and after treatment was discontinued, the number of peripheral blood cells reached a normal level or pretreatment level. In group-1, 5 patients with febrile neutropenia and pneumonia needed antibiotics therapy over 14 days and support treatment of granulocyte colony-stimulating factor (G-CSF). By contrast, there were 6 patients in fourth agents arm. Due to the use of aspirin, no thromboembolic events were observed. In group-1, only $3(7.5 \%, 3 / 40)$ patients reported herpes zoster infection and no further infection symptoms with antiviral prophylaxis in subsequent treatment. Similarly, $7.55 \%$ of patients (4/53) were detected with herpes zoster infection in group-2.

\section{Transplantation}

After 4 cycles of VTD, 7 patients in group- 1 and 8 patients in group- 2 underwent high-dose melphalan, $200 \mathrm{mg} / \mathrm{m}^{2}$ as the conditioning regimen, followed by ASCT. The median $\mathrm{CD} 34^{+}$cells of stem cell collection was $3.68 \times 10^{6}$ cells $/ \mathrm{kg}$ (range, $2.01 \times 10^{6}$ to $5.30 \times 10^{6}$ cells $/ \mathrm{kg}$ ) vs. $5.84 \times 10^{6}$ cells $/ \mathrm{kg}$ (range, $2.17 \times 10^{6}$ to $13.01 \times 10^{6}$ cells $\left./ \mathrm{kg}\right)(\mathrm{P}=0.179)$. The number of mononuclear cells (MNCs) was $6.28 \times 10^{8}$ cells $/ \mathrm{kg}$ (range, $3.97 \times 10^{8}$ to $10.83 \times 10^{8}$ cells $/ \mathrm{kg}$ ) vs. $5.85 \times 10^{8}$ cells $/ \mathrm{kg}$ (range, $3.5 \times 10^{8}$ to $10.56 \times 10^{8}$ cells $\left./ \mathrm{kg}\right)(\mathrm{P}=0.459)$ in group-1 and group-2. In group-1, 4 out of 7 needed a second harvest $(28.6 \%, 2 / 7)$ and third harvest $(28.6 \%, 2 / 7)$ to reach the $2 \times 10^{6} \mathrm{CD} 34^{+}$cells $/ \mathrm{kg}$ required to proceed to transplantation. However, in group-2, only 2 patients (25\%) needed a second stem cell harvest. There was no significant difference in the period of resumption of peripheral blood cells between these two groups, and median days of resumption of peripheral blood cells after infusion stem cell was 13.7 days in group-1 vs. 14.4 days in group- $2(\mathrm{P}=0.138)$. None of the patients experienced transplantation failure.

\section{Discussion}

Multiple myeloma is still an incurable disease with unsatisfactory survival outcomes. Current therapeutic approaches are exploring various combinations, dosage, sequences and duration among glucocorticoids, IMiDs, 
Table 2 Compare the overall response rate (OR) between group-1 and group-2

\begin{tabular}{|c|c|c|c|c|c|c|c|c|c|}
\hline \multirow{2}{*}{ Group } & \multicolumn{9}{|c|}{ Therapeutic outcomes of different groups } \\
\hline & CR & VGPR & PR & $\mathrm{CR}$ & VGPR & PR & CR & VGPR & PR \\
\hline Group-1 (\%) & 20 & 5 & 70 & 45 & 2.5 & 45 & 52.5 & 7.5 & 35.5 \\
\hline Group-2 (\%) & 15.1 & 1.9 & 64.2 & 37.7 & 7.5 & 45.3 & 45.3 & 9.4 & 35.8 \\
\hline
\end{tabular}

CR, complete response; VGPR, very good partial response; $P R$, partial response; ${ }^{*} \mathrm{P}=0.044 ;{ }^{* \star} \mathrm{P}=0.523 ;{ }^{* *} \mathrm{P}=0.349$.

Table 3 Response in ASCT subgroups

\begin{tabular}{|c|c|c|c|c|c|c|}
\hline \multirow[b]{2}{*}{ Response } & \multicolumn{3}{|c|}{ Group-1 $(n=7)$} & \multicolumn{3}{|c|}{ Group-2 (n=9) } \\
\hline & $\begin{array}{c}\text { Pre- } \\
\text { ASCT }\end{array}$ & $\begin{array}{l}\text { Post- } \\
\text { ASCT }\end{array}$ & P-value & $\begin{array}{c}\text { Pre- } \\
\text { ASCT }\end{array}$ & $\begin{array}{l}\text { Post- } \\
\text { ASCT }\end{array}$ & $P$ value \\
\hline CR & 3 & 5 & 0.147 & 3 & 6 & 0.074 \\
\hline VGPR & 1 & 2 & & 2 & 3 & \\
\hline PR & 3 & 0 & & 4 & 0 & \\
\hline
\end{tabular}

ASCT, autologous stem cell transplantation; CR, complete response; VGPR, very good partial response; PR, partial response.

proteasome inhibitors and DNA alkylators to prolong survival and improve quality of life for patients with MM. Currently, VTD is widely used as the induction and consolidation therapy regimen. Opinions on the dose and interval of bortezomib in VTD is mainly divided into different usages. The maximum tolerated level of bortezomib was $1.96 \mathrm{mg} / \mathrm{m}^{2}$, and dose-limiting diarrhea and PN occurred at a dose of $1.56 \mathrm{mg} / \mathrm{m}^{2}(17)$.

The commonly used dose of bortezomib was $1.3 \mathrm{mg} / \mathrm{m}^{2}$ on days $1,4,8$ and 11 , with 10 days of rest (average $1.73 \mathrm{mg} / \mathrm{m}^{2} /$ week). However, PN was the most common adverse event associated with bortezomib, detected in $33-55 \%$ of patients (18-20), and the main cause for dose modification or withdrawal. In the majority of patients, treatment-related PN was reversible. Prolonged duration of dose injection was an efficient therapy for bortezomib associated PN. In this research, group-1 patients who received bortezomib at a dose of $1.6 \mathrm{mg} / \mathrm{m}^{2}$ on days 1,6 and 11 (average $1.6 \mathrm{mg} / \mathrm{m}^{2} /$ week) had a lower incidence of $\mathrm{PN}$ in contrast with group-2; $32.5 \% v s$. $41.5 \%$ respectively $(\mathrm{P}=0.371)$. In group-1, only 1 patient exhibited grade $3 \mathrm{PN}$, and symptoms improved after dose modification. No grade $4 \mathrm{PN}$ was found in either group-1 or group-2. The aforementioned treatment-related hematologic toxicities and infection showed no significant difference between the two groups. Combination with bortezomib at a dose of $1.6 \mathrm{mg} / \mathrm{m}^{2}$, on days 1,6 and 11 appeared to be a well-tolerated treatment in those newly diagnosed with MM.

Several studies have demonstrated that CR and duration to achieved CR was an independent prognostic factor for better survival outcomes $(21,22)$. In this study, 8 patients achieved CR after 2 cycles of VTD-1, and none of them relapsed. All relapsed patients $(n=9)$ achieved PR after 2 cycles of VTD-1, even though the sequential treatment improved response at least VGPR in 3 of 9 patients. During the study, 2 of 8 patients who achieved CR after 2 cycles of VTD-2 relapsed. A total of 24 patients treated with VTD- achieved CR, and 9 of 24 (37.5\%) patients eventually relapsed. The relapse rate in group-2 was much higher than among patients who received VTD-1 as induction and consolidation therapy; $37.5 \%$ vs. $9.5 \%(\mathrm{P}=0.031)$. Meanwhile, after 2 cycles of VTD-1, 95\% (38/40) patients achieved at least PR. The OR rate was much higher than among patients treated with VTD-2 (95\% vs. $81.1 \%$, $\mathrm{P}=0.044)$. Therefore, patients with newly diagnosed $M M$ who received bortezomib $1.6 \mathrm{mg} / \mathrm{m}^{2}$ and dexamethasone $40 \mathrm{mg}$ on days 1,6 and 11 in combination with thalidomide $100 \mathrm{mg}$ on days $1-21$ as induction and consolidation therapy achieved a rapid and deeper response and had a lower risk of relapse.

In the context of novel agent therapy, autologous stem cell transplantation was still an efficient therapy for newly diagnosed MM (23-27), especially for patients who failed to achieve CR from induction treatment. In this study, 15 patients received high-dose melphalan followed by ASCT after 4 cycles of induction therapy. After ASCT, the response of 9 patients was improved, and $77.8 \%$ of patients who achieved PR after induction therapy achieved at least VGPR. For transplantation eligible patients, the induction should have no unfavorable effects on stem cell collection and engraftment. In numerous studies on bortezomib-based combination therapy, there were no harmful effects on stem 
cell harvesting or transplantation (28-30). In this study, even though the median $\mathrm{CD} 34^{+}$cells of stem cell collection was much higher in group-2, there was no significant difference between the two groups $\left(5.84 \times 10^{6}\right.$ vs. $3.68 \times 10^{6}$ cells $/ \mathrm{kg}$, $\mathrm{P}=0.179)$. In group 1 , more than half of the patients who received bortezomib at a dose of $1.6 \mathrm{mg} / \mathrm{m}^{2}$ on days 1,6 and 11 needed a second or third harvest to reach the quantity required to perform transplantation. It appeared that the higher single dose of bortezomib had adverse impacts on stem cell harvesting. However, due to the limitation of the sample size, no statistically significant difference was found in times of stem cell collection $(\mathrm{P}=0.182)$. As previously mentioned, there was no adverse impact on engraftment in this new high-dose bortezomib-based induction therapy.

In conclusion, higher single dose of bortezomib in combination with dexamethasone and thalidomide was well tolerated and efficient as an induction and consolidation therapy for patients with newly diagnosed $M M$ who are ineligible or unwilling to achieve transplantation. High-dose of bortezomib-based induction therapy was not conducive to transplantation, an issue that requires further research.

\section{Acknowledgments}

We would like to thank all the volunteers who took part in this study.

Funding: This work was supported by the National Natural Science Foundation of China (81400162, 81570174), the Six Talent Peaks Project of Jiangsu Province (2018WSN-136), the Jiangsu Provincial Medical Youth Talent and the Technique Development Foundation of Nan Jing (Outstanding Youth Foundation, JQX16099, 17057).

\section{Footnote}

Conflicts of Interest: All authors have completed the ICMJE uniform disclosure form (available at http://dx.doi. org/10.21037/tcr.2019.09.22). The authors have no conflicts of interest to declare.

Ethical Statement: The authors are accountable for all aspects of the work in ensuring that questions related to the accuracy or integrity of any part of the work are appropriately investigated and resolved. The study protocol was approved by the Ethical and Protocol Review Committee of Nanjing University. The number of ethical approval is 2010-13. All procedures performed in studies involving human participants were in accordance with the ethical standards of Nanjing University and with the Helsinki declaration (as revised in 2013) and its later amendments or comparable ethical standards. Written informed consent was obtained from all patients.

Open Access Statement: This is an Open Access article distributed in accordance with the Creative Commons Attribution-NonCommercial-NoDerivs 4.0 International License (CC BY-NC-ND 4.0), which permits the noncommercial replication and distribution of the article with the strict proviso that no changes or edits are made and the original work is properly cited (including links to both the formal publication through the relevant DOI and the license). See: https://creativecommons.org/licenses/by-nc-nd/4.0/.

\section{References}

1. Combination chemotherapy versus melphalan plus prednisone as treatment for multiple myeloma: an overview of 6,633 patients from 27 randomized trials. Myeloma Trialists' Collaborative Group. J Clin Oncol 1998;16:3832-42.

2. Attal M, Harousseau JL, Stoppa AM, et al. A prospective, randomized trial of autologous bone marrow transplantation and chemotherapy in multiple myeloma. Intergroupe Francais du Myelome. N Engl J Med 1996;335:91-7.

3. Bladé J, Rosinol L, Cibeira MT, et al. Hematopoietic stem cell transplantation for multiple myeloma beyond 2010 . Blood 2010;115:3655-63.

4. van de Velde HJ, Liu X, Chen G, et al. Complete response correlates with long-term survival and progressionfree survival in high-dose therapy in multiple myeloma. Haematologica 2007;92:1399-406.

5. Bergsagel PL. Where we were, where we are, where we are going: progress in multiple myeloma. Am Soc Clin Oncol Educ Book 2014:199-203.

6. Badros A, Goloubeva O, Fenton R, et al. Phase I trial of first-line bortezomib/thalidomide plus chemotherapy for induction and stem cell mobilization in patients with multiple myeloma. Clinical Lymphoma \& Myeloma 2006;7:210-6.

7. Bensinger W, Jagannath S, Vescio R, et al. A Phase II Study of Bortezomib (Velcade (R)), Cyclophosphamide (Cytoxan (R)), Thalidomide (Thalomid (R)) and Dexamethasone as First-Line Therapy for Multiple Myeloma. Blood 2008;112:94.

8. Kaufman JL, Nooka A, Vrana M, et al. Bortezomib, thalidomide, and dexamethasone as induction therapy for patients with symptomatic multiple myeloma: a retrospective study. Cancer 2010;116:3143-51. 
9. Nooka AK, Kaufman JL, Muppidi S, et al. Consolidation and maintenance therapy with lenalidomide, bortezomib and dexamethasone (RVD) in high-risk myeloma patients. Leukemia 2014;28:690-3.

10. Dimopoulos MA, Kastritis E, Christoulas D, et al. Treatment of patients with relapsed/refractory multiple myeloma with lenalidomide and dexamethasone with or without bortezomib: prospective evaluation of the impact of cytogenetic abnormalities and of previous therapies. Leukemia 2010;24:1769-78.

11. Palumbo A, Bringhen S, Rossi D, et al. BortezomibMelphalan-Prednisone-Thalidomide Followed by Maintenance With Bortezomib-Thalidomide Compared With Bortezomib-Melphalan-Prednisone for Initial Treatment of Multiple Myeloma: A Randomized Controlled Trial. J Clin Oncol 2010;28:5101-9.

12. Dimopoulos MA, Beksac M, Benboubker L, et al. Phase II study of bortezomib-dexamethasone alone or with added cyclophosphamide or lenalidomide for sub-optimal response as second-line treatment for patients with multiple myeloma. Haematologica 2013;98:1264-72.

13. Brioli A, Melchor L, Cavo M, et al. The impact of intra-clonal heterogeneity on the treatment of multiple myeloma. Br J Haematol 2014;165:441-54.

14. McCarthy PL, Hahn T. Strategies for induction, autologous hematopoietic stem cell transplantation, consolidation, and maintenance for transplantationeligible multiple myeloma patients. Hematology 2013;2013:496-503.

15. Durie BG, Harousseau JL, Miguel JS, et al. International uniform response criteria for multiple myeloma. Leukemia 2006;20:1467-73.

16. Pineda-Roman M, Bolejack V, Arzoumanian V, et al. Complete response in myeloma extends survival without, but not with history of prior monoclonal gammopathy of undetermined significance or smouldering disease. $\mathrm{Br} \mathrm{J}$ Haematol 2007;136:393-9.

17. Kim HJ, Yoon SS, Dong SL, et al. Sequential vincristine, adriamycin, dexamethasone (VAD) followed by bortezomib, thalidomide, dexamethasone (VTD) as induction, followed by high-dose therapy with autologous stem cell transplant and consolidation therapy with bortezomib for newly diagnosed. Ann Hematol 2012;91:249-56.

18. Lonial S, Anderson KC. Association of response endpoints with survival outcomes in multiple myeloma. Leukemia 2014;28:258-68.

19. Gay F, Larocca A, Wijermans P, et al. Complete response correlates with long-term progression-free and overall survival in elderly myeloma treated with novel agents: analysis of 1175 patients. Blood 2011;117:3025-31.

20. Adams J. Development of the proteasome inhibitor PS341. Oncologist 2002;7:9.

21. Richardson PG, Xie W, Jagannath S, et al. A phase 2 trial of lenalidomide, bortezomib, and dexamethasone in patients with relapsed and relapsed/refractory myeloma. Blood 2014;123:1461-9.

22. Richardson PG, Briemberg H, Jagannath S, et al. Frequency, Characteristics, and Reversibility of Peripheral Neuropathy During Treatment of Advanced Multiple Myeloma With Bortezomib. J Clin Oncol 2006;24:3113-20.

23. Gertz MA, Kumar S, Lacy MQ, et al. Stem cell transplantation in multiple myeloma: impact of response failure with thalidomide or lenalidomide induction. Blood 2010;115:2348-53; quiz 2560.

24. Giralt S. Stem cell transplantation for multiple myeloma: current and future status. Hematology 2012;17:S117-20.

25. Palumbo A, Cavallo F, Gay F, et al. Autologous transplantation and maintenance therapy in multiple myeloma. N Engl J Med 2014;371:895-905.

26. Palumbo A. Multiple myeloma. Curr Opin Oncol 2012;24 Suppl 2:S1.

27. Palumbo A, Cavallo F. Have drug combinations supplanted stem cell transplantation in myeloma? Blood 2012;120:4692-8.

28. Harousseau JL, Mathiot C, Attal M. VELCADE/ dexamethasone (vel/D) versus VAD as induction treatment prior to autologous stem cell transplantion (ASCT) in newly diagnosed multiple myeloma (MM): Updated results of the IFM 2005/01 trial. Blood 2007;110:450.

29. Cavo M, Patriarca F, Tacchetti P, et al. Bortezomib (Velcade(R))-Thalidomide-Dexamethasone (VTD) vs Thalidomide-Dexamethasone (TD) in Preparation for Autologous Stem-Cell (SC) Transplantation (ASCT) in Newly Diagnosed Multiple Myeloma (MM). Blood 2012;120:9-19.

30. Stern J. Bortezomib leads to high yield CD34+ collections in MM. Haematologica 2007;92:AbsPO-842.

Cite this article as: $\mathrm{Xu} \mathrm{P,} \mathrm{Zhou} \mathrm{R,} \mathrm{Xu} \mathrm{J,} \mathrm{Ouyang} \mathrm{J,} \mathrm{Shao} \mathrm{X,}$ Chen B. Higher single dose of bortezomib plus thalidomide and dexamethasone is a promising therapy for newly diagnosed multiple myeloma. Transl Cancer Res 2019;8(5):2099-2106. doi: 10.21037/tcr.2019.09.22 